\title{
Studies on Synthesis, Characterization of Modified Phenol Formaldehyde Resin and Metal Adsorption of Modified Resin Derived From Lignin Biomass
}

\author{
S. Arasaretnam a,*, T. Kirudchayini ${ }^{\text {a }}$ \\ ${ }^{a}$ Department of Chemistry, Faculty of Science, Eastern University, Vantharumoolai, Chenkalady, Sri Lanka
}

\begin{abstract}
This study was related to development of economically viable method of extraction of lignin from saw dust in order to produce lignin modified phenolic resin and ecofriendly adhesives (bio-based resin). This study cover to improve the mechanical properties by modification of phenol formaldehyde resole resin using some additives such as boric acid, sulfuric acid and lignin biomass. The synthesis and metal adsorption capacity of resin derived from lignin biomass were explored. Lignin sample was extracted from sawdust of Acacia $s p$. collected from Batticaloa region by alkali extraction method called delignification process. Qualitative tests were carried out on the extracted alkali lignin and it was used to prepare modified resin. Resin synthesized by using lignin substitution phenol and allowed to condensation reaction in the presence of sodium hydroxide. Boron-modified phenol formaldehyde resin was prepared by using boric acid with formalim method. The above reaction was performed for four hours by refluxing with toluene. Which was produced a high viscous massive resin with $90 \%$ yield. The absorbtion peak of B-O bond at $1362 \mathrm{~cm}^{-1}$ was observed at IR spectra. Rise in solid mass content leads to produce smooth resin surface without causing cracks and bubbling. Phenol formaldehyde resin was modified into their sulfonated forms to increase their ion exchange capacity, since the ion exchange capacity of virgin resin was found to be zero. Conductivity property shown by sulfonated resin $(121 \mathrm{mS} / \mathrm{cm})$. The synthesized Lignin based PF resin was used to study the metal adsorption capacity of $\mathrm{Cd}^{2+}$ in aqueous solution. The adsorption capacity of heavy metal $\mathrm{Cd}^{2+}$ ion shown by lignin modified resin $(55 \%)$ and lignin $(86 \%)$. In this study sawdust lignin could be best substitution for phenol in synthesis of Phenol-Formaldehyde resin. It's better due to their sustainability, environmental control, low production cost and their ability to adsorb heavy metals. Phenolic resin was modified with boric acid to improve thermal resistance property and to get smooth resin surface.
\end{abstract}

Keywords:

Phenol Formaldehyde Resin (PFR); Lignin;

Boron Modified Phenolic Resin (BPFR); Lignin Based Phenolic Resin (LPFR); Adsorption Capacity.

Article History:

Received: 21 January 2019

Accepted: $\quad 30$ March 2019

\section{1- Introduction}

The progress of new and modified polymers and their applications leads to improve the manufacture of new products. Polymers differ in their individualities because of their unique structural complexities [1]. Even though polymers are generally classified as elastomers, plastics and fibers, the individuality of the above group vary widely in the sense of arrangement of the monomeric units, change in the conditions for the reaction and type of catalysts [2]. For the last five decades researchers have been extensively exploring all possibilities to discover novel polymers. But now a large amount of work is to directed for the modification of existing polymers [3]. This can be achieved by the addition of modifiers in the initial stage and the reinforcement technique [4].

Plastics are generally classified as thermoplastics and thermosetting plastics [5]. Thermo setting plastics cured into permanent shape through the irreversible crosslinking. This usually occurs under the heat and catalyst it produces three

\footnotetext{
* CONTACT: S_arasaretnam@yahoo.co.uk

DOI: http://dx.doi.org/10.28991/esj-2019-01173

(C) This is an open access article under the CC-BY license (https://creativecommons.org/licenses/by/4.0/).
} 
dimensional cross-linked harden structure. The load-bearing capacity of plastics improved by reinforced with fibers. This could be a better replacement for the traditional building materials like wood and steel due to high strength, chemical resistant withstand ability properties [4, 5]. The phenol-formaldehyde (PF) resol formed by crosslinking of phenol and formaldehyde in the presence of alkali. It could be used extensively due to their low cost, comfort of processing, enduring thermal and chemical resistance, greater dimensional stability and viscosity. Phenolic resins which having low molecular weight are used in laminating paper to reduce the water adsorption. High molecular weight resins commonly used in ply wood glue, thermal insulators and moldings [6].

PF resin with improved thermal stability could be prepared by introducing flame retardant element like bromine to the polymerization reaction [7]. Recent research result shown that Boron modified phenolic resin had lower degree of polymerization than virgin PF in laboratory. The curing kinetics and molecular structure varies depending on the type of boron modifier [8]. The recent growth in industrialization leads to increase petrochemical consumptions. This extreme usage will enhance environmental pollution. So that ecofriendly alternatives for the petrochemicals are essential [7]. PF resins used in wood industrials as their excellent water resistance and heat resistance, [9] but their usage limited by higher cost production and their toxicity. Hence modifications with biomass are essential to overcome these limitations. Nowadays, polymers from renewable resources have the great attention as their environment control, sustainability and low cost for manufacture.

Acacia species are found to be a most specific species in tropical region. They are used in wood industries and the large amount of saw dust threw as waste. Saw dust is the good source of lignin [9]. Hence, the use of Acacia wood powder could be used as a raw material of lignin with the eco-friendly concern. [10, 11] Recent survey shows that the aromatic property of lignin and its ability to participate in radical mediated cross linking and ability to form thermoplastic, make it attractive as a modifier to polymers to enhance physico-chemical properties [12-14].

In this course work, saw dust was used as a raw material for lignin extraction. Extracted alkali lignin was used to prepare P-F resin. Thermal stability and the desired properties were characterized for the modified resins and moreover, the cadmium ion adsorption capacity also investigated for the novel, extracted lignin and bio based resin.

\section{2- Materials and Methods}

\section{2-1- Preparation of PF Resol Resin}

An alkaline catalyst and a molar excess of formaldehyde were used to make resol resins. Resols of varying F: P molar ratios were Synthesized, via. 1.5:1, 2:1 and 2.5:1 and designate as R1.5, R2.0 and R2.5 resins respectively. Phenol and sodium hydroxide were taken into a two necked round bottomed flask. 0.25 mol\% of sodium hydroxide was placed on a phenol basis. The two necked RB flask was provided with a mechanical stirrer and a reflux condenser. Whole system was kept in a water bath and maintained at $90^{\circ} \mathrm{C}$.

Formaldehyde was added at a constant rate with stirring. After the commencement of the reaction a few drops of the reaction mixture was taken at regular intervals of five minutes and added to water until permanent turbidity was obtained, at that stage the mixture was taken out from the water bath and allowed to cool. Alkaline resin was poured into the beaker and neutralized with glacial acetic acid until the $\mathrm{pH}$ reached $\sim 7.0$. The condensate was kept overnight.

\section{2-2- PF Novolac Resins}

An acidic catalyst and a molar excess of phenol to formaldehyde were used to prepare novolac resins. A $5 \mathrm{ml}$ of glacial acetic acid and $2 \mathrm{ml}$ of formaldehyde solution (40\%) were and $2 \mathrm{~g}$ of phenol was added in to it. Beaker was wrapped by a cloth. A few $\mathrm{ml}$ of concentrated hydrochloric acid was added into the mixture carefully and heated slightly. Within five minutes, a large mass of pink plastic was formed. The residue obtain was washed with water, filtered, then dried and determined the product yield. Novolac on heating with formaldehyde undergoes cross linking to form infusible solid mass called Bakelite.

\section{2-3- Preparation of Boron Modified Phenol Formaldehyde Resin}

Modified resol was prepared at the molar ratio of 1.2 formaldehyde /phenol in the presence of Sodium hydroxide catalyst. Setup was placed into round bottomed flask with electrical mechanical stirrer and reflux condenser for 1 hour at $70^{\circ} \mathrm{C}$. followed that boric acid $(0.3 \mathrm{~mol})$ was added and heated for $30 \mathrm{~min}$. after that dehydration was performed under vacuum at $100^{\circ} \mathrm{C}$ until the total extraction of water. The synthesized resin was cured at $170^{\circ} \mathrm{C}$ in the oven for $1 \mathrm{~h}$. Boron modified PF resols were prepared using different amount of boron modifiers as 0.3, 0.5 and 0.8 mol.

\section{2-4- Preparation of Sulfonated Phenol-Formaldehyde Resin}

0.425 moles of phenol was taken into clean $250 \mathrm{ml}$ of tri-neck round Flask. The side neck of the round flask was closed by stop-fit thermometer and closed the other side by a condenser which is connected to water pump, while a stirrer was inserted in the middle neck. The system was run and phenol was heated to appropriate temperature to dissolve any solid bodies. Then the system was stopped and $97 \%$ of sulfuric acid (0.04 moles) was slowly added from one side 
neck by using pipettes. Then the system was operated, while the stirrer was adjusted to appropriate speed and the temperature was raised, which was maintained between $100-120^{\circ} \mathrm{C}$ for two hours. After that the system was stopped and cooled slowly, then placed in ice path, 0.12 moles of Formaldehyde was added by using pipettes, a fizzing and bubbling were occurred, the temperature was cooled to $35^{\circ} \mathrm{C}$ then below $22^{\circ} \mathrm{C}$ by stirring with glass rod. Stirring was continued until a viscose solid mass was obtained. The product was left overnight. $\mathrm{pH}$ was examined by using indicator paper and $\mathrm{NaOH}$ solution drops were added until over saturation was reached to high $\mathrm{pH}$, a few drops of $\mathrm{H}_{2} \mathrm{SO}_{4}$ was added for equilibrium reach until $\mathrm{pH}=7$.

\section{2-5- PF Resole Modified with Lignin}

\section{2-5-1- Preparation of Sawdust for Extraction}

Sawdust was obtained from the local timber mill and shifted through the sieve having mesh size of $1 \mathrm{~mm}$ and dried in an oven at temperature of $105^{\circ} \mathrm{C}$ during 1-2 days until obtained constant weight. Saw dust sample was boiled with hot water during $4 \mathrm{hrs}$. and filtered to remove the water soluble matters such as tannins, gums, sugars and colorants. Solid residue was dried in oven at $105^{\circ} \mathrm{C}$ during 1-2 days until achieved constant weight.

\section{2-5-2- Extraction of Lignin}

Lignin is extract from sawdust by alkali extraction method. $50 \mathrm{~g}$ of prepared saw dust was placed into a beaker and $300 \mathrm{ml}$ of $\mathrm{NaOH}(5 \mathrm{M})$ solution was poured into it then heated about $140^{\circ} \mathrm{C}$ for 7 hours. Then the content was filtered and washed with $\mathrm{NaOH} 2-3$ times. It was heated to evaporate the solvent at $100^{\circ} \mathrm{C}$ during 2 days, to isolate the lignin from liquid part. And the precipitate was dried in oven at $105^{\circ} \mathrm{C}$ during 2 days.

\section{2-5-3- Lignin Purification}

Extracted lignin sample was refluxed with acetic acid for 4 hours, to remove impurities. Then it was filtered and washed with acetic acid for 2-3 times. Then the solution was heated at $100^{\circ} \mathrm{C}$ for 2 days. Lignin precipitate was cured in an oven at $105^{\circ} \mathrm{C}$ for 2 days.

\section{2-5-4- Lignin Identification}

Lignin was analysed by qualitative methods as, Lignin was treated with phenol and $\mathrm{HCl}$, and greenish blue colour was obtained. Then lignin was treated with aniline sulphite then it was turned to yellow colour.

\section{2-5-5- Synthesis of Lignin Based PF Resin}

$20 \mathrm{ml}$ of phenol, $15 \mathrm{ml}$ formaldehyde, $0.5 \mathrm{~g}$ of extracted alkali lignin and $0.5 \mathrm{~g}$ of sodium hydroxide were placed in a beaker equipped with a mechanical stirrer. It was heated at $80{ }^{\circ} \mathrm{C}$ for 45 minutes. Setup was cooled to $40{ }^{\circ} \mathrm{C}$ in order to stop the reaction. Finally, resin was cured at $110^{\circ} \mathrm{C}$ for 3 hour in an oven.

\section{2-6- Analysis of Synthesized Resin}

- Mechanical properties were quantified.

- Conductivity of the resin was determined by conductivity meter.

Density was determine by Mass of unit volume

\section{- Total solid content (TSC)}

An accurately weighed sample (about $0.5 \mathrm{~g}$ ) was evaporated to dryness at $170^{\circ} \mathrm{C}$ for $30 \mathrm{~min}$

\section{- Gel time}

A weighed amount of resin was filled into a test tube and dipped into an oil bath at $130^{\circ} \mathrm{C}$.

The increase in viscosity was identified with a glass rod used like a piston. The gel point of the resin was identified as the instant when the glass rod gets stuck in the resinous mass.

\section{- Swelling test}

A piece of Rubber was placed in a stoppered bottle containing toluene sufficient quantity to cover the rubber piece.

$$
\text { Swell percentage }=\frac{W_{\text {after swelling }}-W_{\text {initial }}}{W_{\text {initial }}}
$$

\section{Characterization of resin in Fourier transform infrared spectroscopy (FTIR) analysis}

Lignin modified PF resin was investigated by Fourier transform infrared spectrophotometer (FTIR) in the wave length $400-4000 \mathrm{~cm}^{-1}$. 


\section{2-7- Metal Adsorption Capacity of Prepared Lignin Based Resin}

In order to investigate the metal adsorption capacity, 2 grams of resins were mixed with $10 \mathrm{ml}$ solution of cadmium ion $\left(\mathrm{Cd}^{2+}\right)$. The mixture was incubated for 24 hour at room temperature with constant stirring. Mixture was filtered after 24 hours. Amount of metal adsorption was determined by using Atomic Absorption Spectrometer. Adsorption capacity at equilibrium state was determined according to the Langmuir equation [15].

$$
q e=\frac{C o-C e}{D}
$$

Where, $\mathrm{Co}$ - initial metal concentration in solution; $\mathrm{Ce}$ - equilibrium metal concentration in solution; $D$ - Sample dose.

A summary of research methodology displayed in Figure 1.

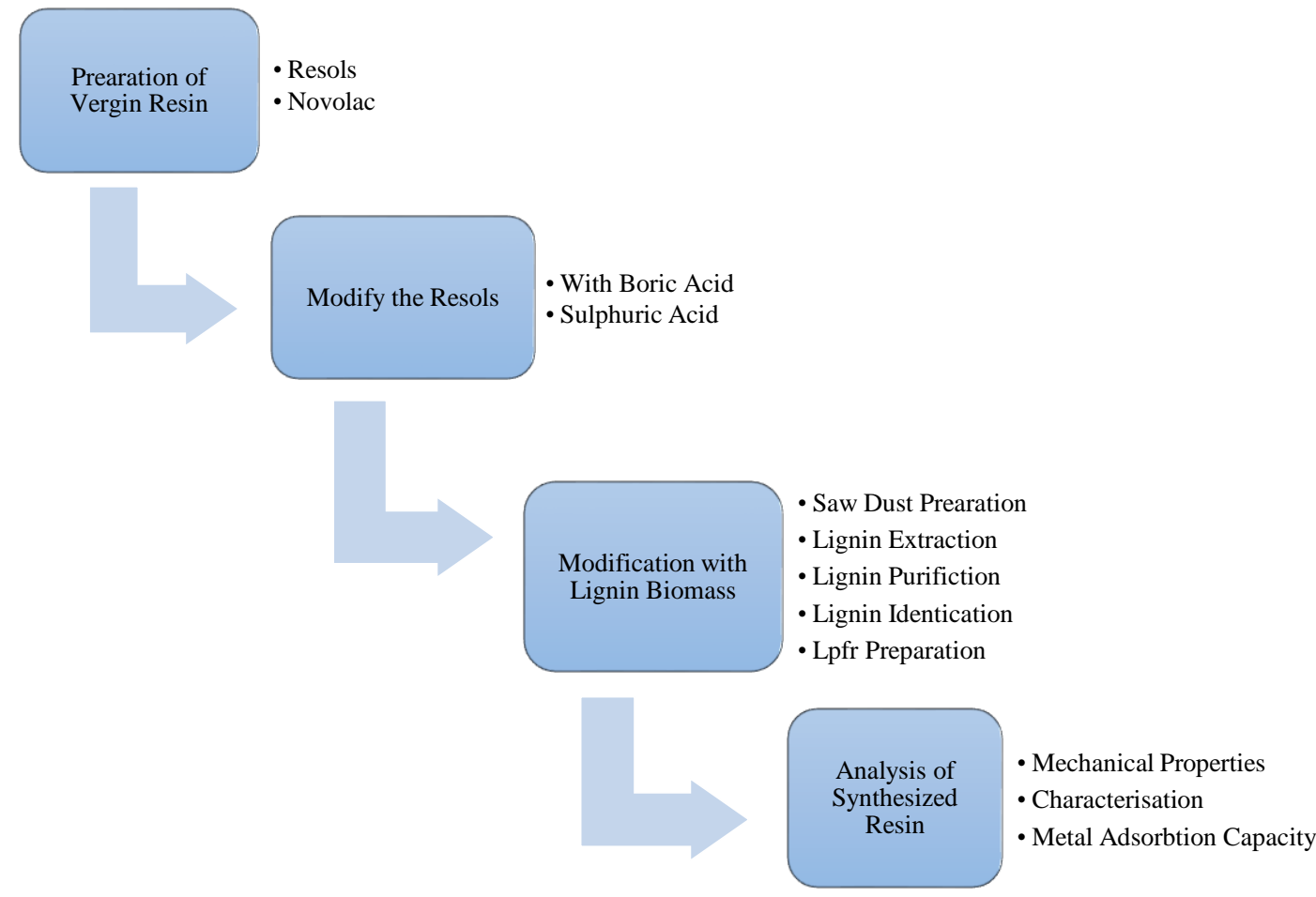

Figure 1. Flow chart for the research methodology

\section{3- Results and Discussion}

\section{3-1- Uncured and Cured Phenolic Resin}

At the end of the reaction at $90^{\circ} \mathrm{C}$, a solutions having high viscosity was obtained for all resin. Alkaline medium with molar excess formaldehyde used to form resols resins. This condensation Reaction leads to the three dimensional network product having high molecular weight. It causes the resin to gel which is attributed to the high viscosity of the solution. The free hydroxyl groups of the phenol in the resin are mildly acidic and dissociate partially in water. But in the presence of the base $(\mathrm{NaOH})$ they form alkoxide salts (of Sodium). These salts are ionic and completely dissociate in water due to the strong ion-dipole bonding leads water soluble resin. However when the medium is acidified with $\mathrm{HCl}$ the free hydroxyl groups are regenerated, restrict the resin soluble in water. Eventually the resin solidifies and separates out of the solution as a precipitate.

The synthesised resin showed a variation in colour and strength. Virgin phenol formaldehyde resols (PFR), that had no additives, displayed a cream colouration. And pure phenol formaldehyde novolac resin (PFN) displayed a pink colouration. Resoles were exhibit more rigidity than Novolac resin.

\section{3-2- Analysis of the Boron Modified Phenolic Resin}

Boron containing phenol Formaldehyde resin synthesized using formalin method, as the reaction form alcohol followed with the addition of boric acid. Boric acid modified resin displays some advantageous properties given below (Table 1). Solid mass content of modified resins diverse in the range of $90-96 \mathrm{w} / \mathrm{w} \%$, Content of free formaldehyde was about ten times lower in assessment with virgin resin. Free phenol content was also decreased compare to unmodified resin. The higher Solid mass content indicates that a less amount of water and low molecular weight components. Hence, presence higher solid mass content undesirably affects the curing process which cause bubbling and form cracks on the surface. 
Table 1. Characterization of phenol-formaldehyde resoles modified by boric acid

\begin{tabular}{ccccc}
\hline \multirow{2}{*}{ Properties of the resin } & \multicolumn{3}{c}{ Amount of modifiers (mol) } \\
\cline { 2 - 5 } & $\mathbf{0}$ & $\mathbf{0 . 3}$ & $\mathbf{0 . 5}$ & $\mathbf{0 . 8}$ \\
\hline Solid mass content, (wt. \%) & 62.0 & 95.0 & 92.0 & 0.20 \\
\hline Free formaldehyde content, (wt. \%) & 2.50 & 0.25 & 1.8 & 2.1 \\
\hline Free phenol content, $(\%)$ & 6.3 & 1.5 & 130 & 130 \\
\hline Curing temperature, $\left({ }^{\circ} \mathrm{C}\right)$ & 160 & 172 & & 0.16 \\
\hline
\end{tabular}

According to the Figure 2, the typical absorption band of $\mathrm{Ar}-\mathrm{CH}_{2}-\mathrm{OH}$ observed at $1039 \mathrm{~cm}^{-1}$, modified resin shortened the peak compare to virgin. B-O absorption peak was appeared at $1362 \mathrm{~cm}^{-1}$. The main bands are in agreement with the bands coming from boron and the alcohol. The region at $3381 \mathrm{~cm}^{-1}$ shows characteristic bands for-OH group of alcohol and acid. Boric acid (B-OH) has a strong and characteristic band at $1515 \mathrm{~cm}^{-1}$.

\section{3-3- Sulfonated Phenolic Resols}

As a result of refluxing with concentrated $\mathrm{H}_{2} \mathrm{SO}_{4}$, sulfonated resols were obtained, displayed an orange colouration. Resols substituted strong ion exchanger sulfonic acid groups. These sulfonated resins are bi-functional since they contain sulfonic (strong acidic) and hydroxyl (week acidic) groups directly attached to the aromatic rings. Sulfonated Phenol Formaldehyde Resol (SPFR) was completely insoluble in water due to the increased molecular weight.

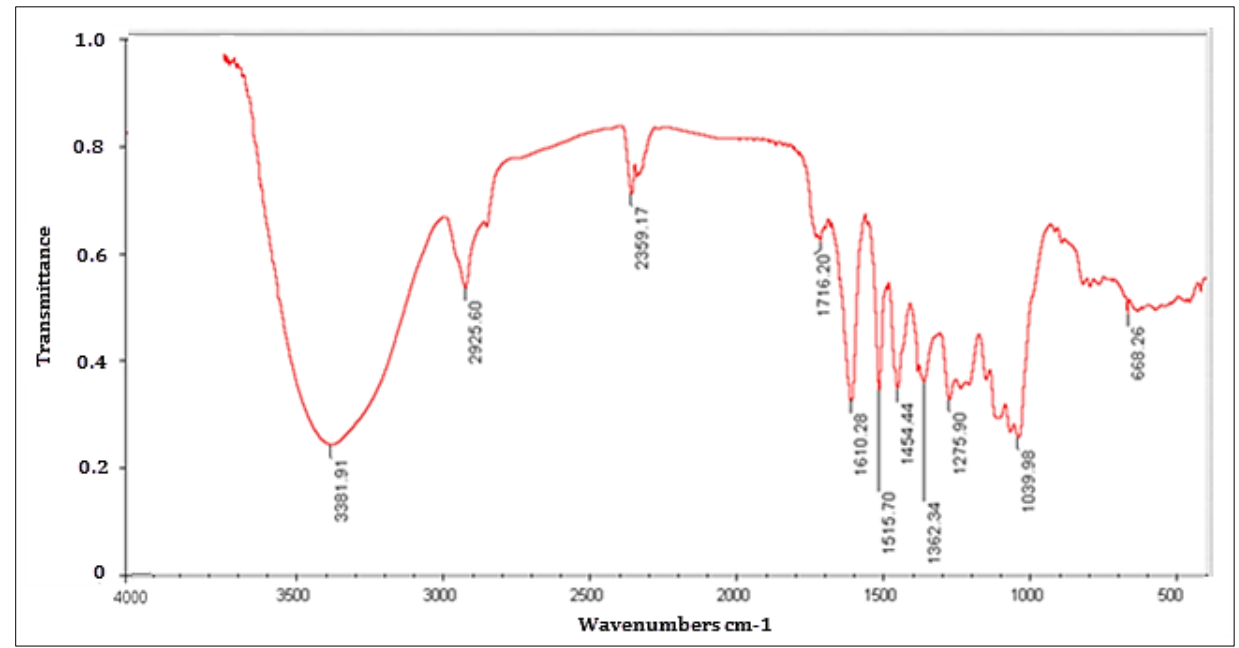

Figure 2. FT-IR spectrum of the Borated phenolic resin

\section{3-4- Analysis of Lignin Based PF Resin}

\section{3-4-1-Extraction of Lignin}

Lignin molecules are large and possess several reaction sites, formation of three dimensional networks would be the possible end product. Extraction carried out by delignification process, and Soda lignin was obtained from black liqueur as shown in Figure 2.

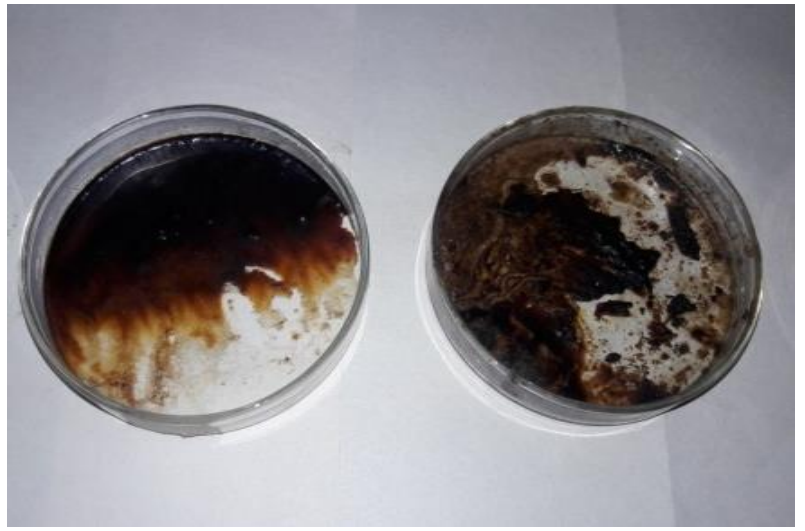

Figure 3. Resin obtained from black liqueur 


\section{3-4-2- Qualitative Analysis of Extracted Lignin}

Greenish blue colouration obtained from lignin treated with phenol and $\mathrm{HCl}$. And Yellow colouration obtained from lignin treated with aniline sulphite.

\section{3-4-3- Quantitative Analysis}

$$
\text { Lignin, } \%=\frac{A \times 100}{W}
$$

Where: $\mathrm{A}=$ weight of lignin, $\mathrm{g} ; \mathrm{W}=$ oven-dry weight of extractive-free sawdust, $\mathrm{g}$, So the yield percentage of isolated lignin was $33 \%$.

$\frac{5 g}{15 g} \times 100=33.33 \%$

\section{3-4-5- UV Spectral Analysis of LPFR}

UV spectrum had an absorption maximum at wavelength of $210 \mathrm{~nm}$, and the second maximum was at $278 \mathrm{~nm}$. The appearance of two characteristic peaks in the lignin spectrum originated from non-condensed phenolic groups (aromatic ring) in lignin. Small portion of unsaturated aliphatic units contained in lignin molecule also results in peak. Therefore, the absorbance maximum value at short wavelength was higher than that at long wavelength. The absorbance of UV spectra is directly proportional to the purity level of lignin.

\section{3-4-6- FTIR Analysis of Acacia Saw Dust Lignin Based Resin}

Adsorption peaks was observed around at $3372 \mathrm{~cm}^{-1}$, which characterizes hydroxyl groups (-OH) of lignin. The peak at $2956 \mathrm{~cm}^{-1}$ characterizes $\mathrm{C}-\mathrm{H}$ vibration of methylene groups and at $2553 \mathrm{~cm}^{-1}$ characterizes $\mathrm{C}-\mathrm{H}$ vibration of methoxy groups as displayed in Figure 4.

The characteristic peaks of lignin attributed at $1590 \mathrm{~cm}^{-1}$, resembles to the aromatic skeleton of lignin. Peak at 1472 $\mathrm{cm}^{-1}$ attributed to the methylene groups $(\mathrm{C}-\mathrm{H})$ and the $\mathrm{C}-\mathrm{O}$ ether band displayed at $1233 \mathrm{~cm}^{-1}$.

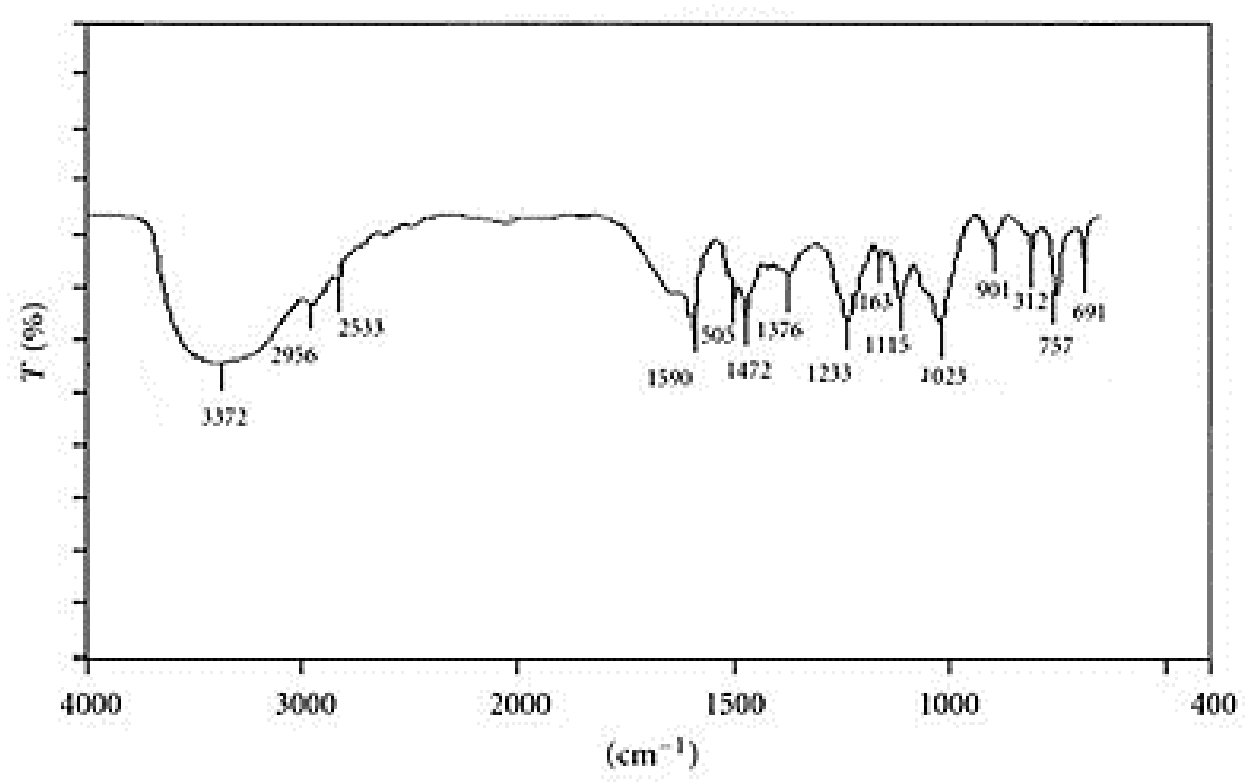

Figure 4. FTIR analysis of lignin based Phenol formaldehyde resole

\section{3-4-7- Metal ion Adsorption Capacity of Lignin Based PF}

Polyphenols have the capacity to form complexes with heavy and transition metals. Thus, synthesized lignin based resin as well as lignin also showed that the ability to adsorb $\mathrm{Cd}^{2+}$ ion as shown in Table 2 . These are the good adsorbers of heavy metals; it could be suggested to use in water purification plants. The highest metal adsorption capacity was detected by alkali lignin as $86 \%$. 
Table 2. Metal ion absorption capacity of lignin based phenolic resin

\begin{tabular}{|c|c|c|c|c|}
\hline Sample & $\begin{array}{l}\text { Initial concentration } \\
\text { of } C d^{2+}(\mathrm{ppm})\end{array}$ & $\begin{array}{l}\text { Final concentration } \\
\text { of } C d^{2+}(\mathrm{ppm})\end{array}$ & $\begin{array}{c}\text { Amount of } \\
C d^{2+} \text { absorbed (ppm) }\end{array}$ & $\begin{array}{c}\text { Metal absorbed } \\
(\%)\end{array}$ \\
\hline Control PF resin & 0.182 & 0.182 & 0.182 & 0.0 \\
\hline Lignin based resin & 0.182 & 0.082 & 0.10 & 55 \\
\hline Extracted Alkali Lignin & 0.182 & 0.024 & 0.158 & 86 \\
\hline
\end{tabular}

Initial and final concentration of Metal ion in prepared ionic solution was determined by Atomic Absorption Spectroscopy. Lignin is a highly cross-linked aromatic compound. The highest metal adsorption capacity was offered by alkali lignin as related to lignin based resin. This could be feasible because of their large porous. The adsorption of $C d^{2+}$ ion was formed through the electro static interaction of $C d^{2+}$ ion with the resin mass.

\section{3-5- Mechanical Properties of Modified Resins}

As shown in Table 3; Conductivity, the ion exchange property was observed in Sulfonated PF resin. The gelation time of the phenolic resole decreases with increase in the F/P molar ratio. This is due to the progressive increase in the methylol groups as the amount of formaldehyde increases. The increase in the number of methylol groups speeded up the crosslinking reaction and resulted in an early attainment of the gel point [9]. The TSC is seen to remain almost constant for resins with various F: P molar ratios. Variations in the TSC lead to a decrease or increase in the dimensions of the castings. Thermal stability was analyzed by gel time. If the gel time increases, the thermal stability proportionally increase. Boron and lignin modified PF resoles were more thermally stabilized than virgin PF resole.

Table 3. The variation of physical properties Table for modified resins

\begin{tabular}{ccccc}
\hline Property & $\begin{array}{c}\text { Phenol Formaldehyde } \\
\text { resole (PF) }\end{array}$ & $\begin{array}{c}\text { Boron modified PF } \\
\text { resole (BPFR) }\end{array}$ & $\begin{array}{c}\text { Sulfonated PF resole } \\
\text { (SPFR) }\end{array}$ & $\begin{array}{c}\text { Lignin modified PF } \\
\text { resole (LPFR) }\end{array}$ \\
\hline Conductivity (mS/cm) & 0 & 0 & 121 & 0 \\
\hline TSC (total solid content) $\%$ & 52.72 & 55.32 & 42.31 & 2008 \\
\hline Gel time (sec.) & 472 & 1072 & 31 & 842 \\
\hline Swell percentage $(\%)$ & 20 & 15 & & 25 \\
\hline
\end{tabular}

\section{4- Conclusion}

Modified resins were prepared for improve mechanical properties. Acacia sp lignin was effectively suited for the modification of PF resin with the effective environmental control. The Acacia sp lignin based resin has similar characteristics as observed for the virgin phenol-formaldehyde resin. FTIR study displays that lignin-PF resin interaction. Lignin modified resin found to be a highly thermally stabilized than virgin PF resin as the gel time of LPFR is higher than virgin PFR. Rather than that, the lignin based resin showed increased heavy metal adsorption capacity. PF resins used in timber industrials as their excellent wetting and heat resistance, thus there are some limitations due to expenses and hazardous. Hence, the modifications with biomass are essential to overcome these limitations. This could be efficient alternative for the PF resin with the eco-friendly manner and due to bearing strength. Moreover, Lignin based phenolic resins suggested to install in the heavy metal polluted areas to adsorb pollutants as an environmental friendly manner. And also LPFR suggested using in wood industries as eco-friendly Bonding glue. The use of boric acid as a modifier in Phenol Formaldehyde resin leads to decrease the free monomers and increase the solid mass, which leads to produce smooth resin surface without causing cracks and bubbling. Boric acid modification resulted non-toxic resin compositions and increase in thermal resistance so their flammability becomes smaller. Boron modified resins suggested to use in burning products, electrical goods manufacturing field.

\section{5- Data Availability}

The data used to support the findings of this study are available from the corresponding author upon request.

\section{6- Funding and Acknowledgements}

This research was supported by Department of Chemistry, Eastern University, Sri Lanka. Author was very grateful for the support of technical staffs of Eastern University, Sri Lanka for their consistence support by providing essential materials and Mr. Herath, (Department of Chemistry, University of Colombo, Sri Lanka) for the arrangement of IR spectroscopy. 


\section{7- Conflict of Interest}

The authors declare no conflict of interest.

\section{8- References}

[1] Parameswaran, P. S., and Eby Thomas Thachil. "Influence of Ether Linkages on the Properties of Resol Phenolic Resin." International Journal of Polymeric Materials and Polymeric Biomaterials 56, no. 2 (November 23, 2006): $177-185$. doi:10.1080/00914030600773602.

[2] Żihorska-gotfryd, Anna. "Phenol-formaldehyde resols modified by boric acid." Polimery 51, no. 5 (2006).

[3] Glasser, and Wolfgang G. Studies of low molecular weight lignin sulfonates. Vol. 1. For sale by the Supt. of Docs., US Govt. Print. Off., 1974.

[4] Nada, Abda - Alla M. A., Hussein Abou - Youssef, and Souad E. M. El - Gohary. "Phenol Formaldehyde Resin Modification with Lignin.” Polymer-Plastics Technology and Engineering 42, no. 4 (January 9, 2003): 689 - 699. doi:10.1081/ppt-120023103.

[5] Mankar, S. S., A. R. Chaudhari, and I. Soni. "Lignin in phenol-formaldehyde adhesives." International Journal of Knowledge Engineering, ISSN (2012): 0976-5816.

[6] Yang, Guangyu, and Pirjo Jaakkola. "Wood chemistry and isolation of extractives from wood." Literature study for BIOTULI project-Saimaa University of Applied Sciences (2011): 10-22.

[7] Masram, Dhanraj T., K. P. Kariya, and N. S. Bhave. "Electrical conductivity study of resin synthesized from salicylic acid, butylenediamine and formaldehyde." Archives of Applied Science Research 2, no. 2 (2010): 153-161.

[8] Jablonský, M., J. Kočiš, A. Ház, and J. Šima. "Characterization and comparison by UV spectroscopy of precipitated lignins and commercial lignosulfonates." Cell. Chem. Technol 49, no. 3-4 (2015): 267-274.

[9] Chai, Yubo, Junliang Liu, Yong Zhao, and Ning Yan. "Characterization of Modified Phenol Formaldehyde Resole Resins Synthesized in Situ with Various Boron Compounds." Industrial \& Engineering Chemistry Research 55, no. 37 (September 12, 2016): 9840-9850. doi:10.1021/acs.iecr.6b02156.

[10] Strap, Galyna, Olena Astakhova, Olexander Lazorko, Oleh Shyshchak, and Michael Bratychak. "Modified phenol-formaldehyde resins and their application in bitumen-polymeric mixtures." (2013).

[11] Keshaw Ram Aadil, Rajan Jha, Harit Jha. "Synthesis, characterization and metal adsorption capacity of Acacia lignin based resin.” Asian Journal of Biological and Life Sciences 5, no. 1: 40-45.

[12] Li, Jiongjiong, Wenjie Zhu, Jizhi Zhang, Shifeng Zhang, Qiang Gao, Jianzhang Li, and Wei Zhang. "Curing Properties of HighOrtho Phenol-Formaldehyde Resins with Co-Catalysis.” Journal of Applied Polymer Science 136, no. 12 (November 23, 2018): 47229. doi:10.1002/app.47229.

[13] Kalami, Somayyeh, Nusheng Chen, Hamid Borazjani, and Mojgan Nejad. "Comparative Analysis of Different Lignins as Phenol Replacement in Phenolic Adhesive Formulations." Industrial Crops and Products 125 (December 2018): 520-528. doi:10.1016/j.indcrop.2018.09.037.

[14] Zhi, Maoyong, Xiantao Chen, Quanyi Liu, and Jingyun Jia. "Improved Mechanical Properties and Thermal Stability of Phenol Formaldehyde Resin by Incorporating Poly(vinyl Alcohol)-Grafted Reduced Graphene Oxide Nanohybrid.” Materials Research Express 5, no. 9 (August 10, 2018): 095306. doi:10.1088/2053-1591/aad6c2.

[15] Grossman, Adam, and Wilfred Vermerris. "Lignin-Based Polymers and Nanomaterials.” Current Opinion in Biotechnology 56 (April 2019): 112-120. doi:10.1016/j.copbio.2018.10.009. 